Research Article

\title{
Sales Associations between Brand Stores Based on Spatial Interaction Effects
}

\author{
Yuepeng Sui $\mathbb{D}^{1},{ }^{1}$ Guoxin $\mathrm{Li} \mathbb{D}^{1},{ }^{1}$ and Jiaoju Ge $\mathbb{C}^{2}$ \\ ${ }^{1}$ School of Management, Harbin Institute of Technology, Harbin 150001, China \\ ${ }^{2}$ School of Management, Harbin Institute of Technology (Shenzhen), Shenzhen 518055, China \\ Correspondence should be addressed to Guoxin Li; liguoxin@hit.edu.cn and Jiaoju Ge; jiaoge@hit.edu.cn
}

Received 25 March 2021; Accepted 24 May 2021; Published 1 June 2021

Academic Editor: Musavarah Sarwar

Copyright (c) 2021 Yuepeng Sui et al. This is an open access article distributed under the Creative Commons Attribution License, which permits unrestricted use, distribution, and reproduction in any medium, provided the original work is properly cited.

There is a dearth of research concerning location-based service (LBS), including its determinants and antecedents. However, it is still unclear how LBS influences a brand store's profit with the consideration of surrounding stores. To fill the gap, this study focuses on the influence of surrounding store information on sales of a brand store from the perspective of LBS. By analyzing spatial data, sales data, and shopper flow data of 737 brand stores for a large shopping mall in China with spatial Dubin model, this study identifies several findings: (1) sales and shopper stay times in surrounding stores can negatively influence sales of a brand store; (2) store types can moderate the relationship between the sales of surrounding stores and those of a brand store; (3) shopper flow in surrounding stores can also influence the sales of a brand store depending on the volume of shopper flow at different times in a day. This study has implications for academics and practitioners.

\section{Introduction}

The mobile Internet and Internet of Things (IoT) are shaping a new retail form, in which mobile devices allow marketers to contact shoppers directly and shoppers to obtain and share product information in real-time. This new retail form has great impact on retailers and shoppers. For example, more than $80 \%$ of US shoppers use mobile devices to search for product information even within an offline store (Google M/A/R/C Study, 2013) (Google M/A/R/C Study (2013), "Mobile In-store Research: How In-store Shoppers Are Using Mobile Devices”. https://ssl.gstatic.com/think/docs/ mobile-in-store_research-studies.pdf.).

The mobile Internet and the IoT facilitate the acquisition of shopper location information by brick and mortar shops, thus providing support for developing location-based services (LBSs). An LBS is defined as a network-based service that can utilize location information and other information to provide added value to the user $[1,2]$. It has wide coverage, high positioning accuracy, easy operation, and wide application, thus receiving great attention from prior scholars. The existing research has mainly focused on the technology problems faced during the usage of LBS [3-5] and the determinants, as well as antecedents, of LBS adoption [2, 6-9]. For instance, LBS usage not only influences shoppers' decision-making, but also affects shoppers' sentiment $[8,9]$. Several factors can explain why shoppers adopt or refuse LBSs, including privacy concerns [6], perceived enjoyment [10], and perceived service value of LBSs [11]. However, it is still unknown how LBSs can influence a brand store's profit when considering the surrounding stores. To fill the research gap, this study focuses on the influence of surrounding store information on sales of a brand store from the perspective of LBS.

The study selects shopping malls as a representative retail scenario. By combining store location and sales data with shopper flow data in a shopping mall, this study identifies several findings: (1) sales and shopper stay times in surrounding stores can negatively influence sales of a brand store; (2) store types can moderate the relationship between the sales of surrounding stores and that of a brand store; and (3) shopper flow in surrounding stores can also impact the sales of a brand store, and this effect depends on shopper flow that happens at different time periods in a day. This 
study makes several contributions. First, it introduces the concept of limited attention in the context of LBS as limited attention facilitates the rule-out effect of sales of surrounding stores on that of a brand store. The identification of how shoppers' limited attention can induce competitive relationships between surrounding stores is uncovered in the existing literature on limited attention. Second, this study complements the herding influence literature by exploring how stores with difference features can induce different shopper gathering and herding influence, playing a determinant role in changing the competitive relationships among surrounding stores. Third, this study extends consumer behavior literature by introducing LBSs into the context of offline shopping malls. The usage of LBSs can deepen the understanding of positional factors that may affect the sales of a brand store. This study highlights the importance of LBSs from a practical perspective and provides suggestions for operators in shopping malls about location strategies for different types of stores.

\section{Literature Review and Research Hypotheses}

2.1. Sales Associations between Brand Stores. Enclosed shopping malls become popular in several countries [12]. Existing studies have investigated store relationships in shopping malls, especially the competitive relationship between different stores within a shopping mall. In these studies, stores mainly refer to different types of stores in the same industry [13]. Later study has begun to focus on competition among stores in different industries and consider store locations as competitive factors [14]. For example, by investigating the space competition of retail stores, Aguirregabiria and Vicentini established a dynamic model of store space competition [15], and Davis estimated market demand based on store space competition [16]. Bronnenberg and Mahajan focused on sales of Mexican hot sauce and nachos in different United States regions and identified a certain spatial dependence on neighboring companies or stores [17]. Luca and Zervas noted that location factors could cause competition between surrounding restaurants, becoming a determinant of the generation of false evaluations on Yelp [18]. The situation is similar for the hotel industry on TripAdvisor [19].

In sum, previous studies mainly explored the relationship between stores from the perspective of cities, streets, and neighborhoods. This study limits the research scope to a more restricted scope, namely, a shopping mall. In a shopping mall, the target store is set as the "brand store," and other stores are set as "surrounding stores." As shown in Figure 1, shops A, B, C, D, and $E$ have similar styles and relatively uniform price ranges with store $\mathrm{B}$ as "brand store" and stores A, C, and D as "surrounding stores."

Attention is a scarce cognitive resource that individuals have limited quantities of attention [20]. During the shopping process, shoppers have limited attention for stores and limited budgets for goods. Thus, shoppers need to allocate their limited attention and budgets to a brand store when wandering around a shopping mall. For a shopper, making purchase decisions in a brand store may reduce his/

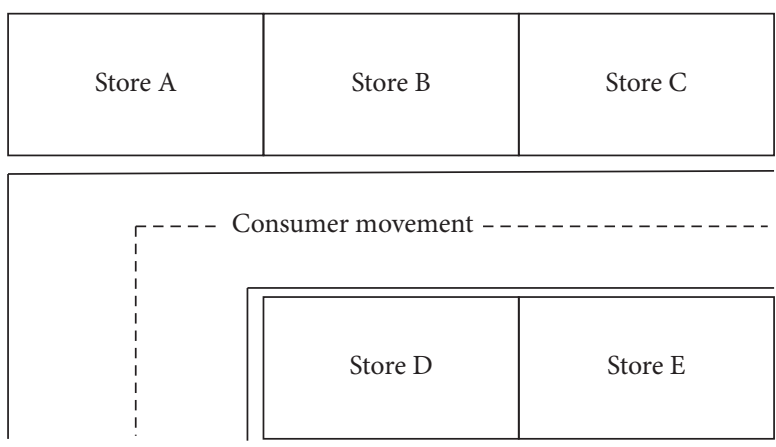

FIgURE 1: Diagram of the location relationship between a brand store and surrounding stores.

her limited attention and budget for other stores, thus restricting sales of other stores. The situation is especially prominent when other stores are near the brand store, as a shopper's attention can hardly recover to normal levels within a short time (distance) [21]. In other words, surrounding stores (a brand store) tend to suffer from a shopper's purchase decisions at a brand store (surrounding stores). Therefore, our first hypothesis is

$\mathrm{H} 1$ : the sales of surrounding stores have a significant negative impact on the sales of a brand store

2.2. The Moderating Role of Store Types. Compared with fashion stores, catering stores are more likely to gather large numbers of shoppers in a short time period. For example, during lunchtime, the catering store areas are the most popular places in any shopping mall. Based on herding influences, catering stores with clustered shoppers tend to appeal to more shoppers [22]. Thus, shopping malls usually put catering stores together in a relatively dense space. Since shopper demand and utility are both a decreasing linear function of purchase distance, a longer (shorter) distance between stores may have a negative (positive) effect on shopper attitude and purchase decisions [23]. Compared to other stores, catering stores are located at a relatively dense space, and shoppers may form favorable attitudes and make more purchases towards these stores. Thus, the second hypothesis is

$\mathrm{H} 2$ : types of brand stores moderate the relationship between the sales of a brand store and surrounding stores

2.3. Shopper Stay Time and Brand Store Sales. Consumer behavior studies have highlighted the important role of shopper stay time [24-26]. Hui et al. divided a shopper's decision-making process into three stages: visiting, shopping, and purchasing [27]. Visiting and purchasing are quick action. Shopping is a process of selecting and deciding, which requires a relatively more extended period. Thus, the process of shopping is strongly associated with shopper stay time in a store. In prior studies, the relationship between the length of shopping time and product purchases has been identified [24, 26]. That is, a longer shopping time can 
increase the possibility that a shopper purchases a product $[26,28]$. Thus, for a brand store whose surrounding stores induce shoppers to stay longer, shoppers may give their limited attention and budget to surrounding stores rather than the brand store, thus reducing the sales of a brand store. Thus, our third hypothesis is

$\mathrm{H} 3$ : the sales of a brand store are significantly negatively affected by shopper stay time in surrounding stores

2.4. Shopper Flow and Sales of Brand Stores. For stores within a shopping mall, real-time shopper flow can be helpful to understand shopper purchase habits and the reasons for sales changes, thus increasing the store sales [29]. Shopper flow data for a store also plays a crucial role in deciding the store's rent and location, as well as the entry or exit choices of different brands [30]. Hence, sorting and analyzing shopper flow data become a prerequisite for shopping malls and stores to manage their business [31]. Shopper flow can also reflect the attention allocation of shoppers. That is, when shopper flow of surrounding stores is high, shoppers are likely to give their attention and even budgets to surrounding stores. In this way, little attention and budget are left for a brand store, thus reducing the brand store's sales.

In traditional marketing theory, the shopping cost can be categorized into four parts: money, time, physical strength, and spiritual cost. The cost of time is relatively easier to reduce by optimizing the building design or location allocation, thus becoming a main focus when investigating retailing-related questions [32, 33]. For example, Michelle identified that future-oriented individuals are more likely to control the consumption process, minimize the involvement of commercial intermediaries, and spend more time to collect product information [33], while present-oriented individuals intend to entrust the shopping process to others, including sales consultants and commercial intermediaries. Thus, the time that a shopper enters a shop may decide his/ her evaluations and behavior towards products [34]. Thus, we propose the last hypothesis:

H4: different time periods will moderate the relationship between the shopper flow of surrounding stores and the sales of a brand store

The research framework is presented in Figure 2.

\section{Methodology}

3.1. Data. We use shopper flow data and sales data of stores in a shopping mall of China collected by a third-party data provider. It contains 74,561 shopper flow data from September 22, 2016, to October 13, 2016. After deleting empty shops and other noneligible information, 61,842 eligible shopper flow pieces of data were left, with a valid data rate of $82.94 \%$. Sales dataset contains 16,214 pieces of data from 737 stores.

Figure 3 presents age distribution of shoppers and shows that the shoppers were concentrated between the ages of 30 and 40. Shoppers among these ages are more fashionconscious and have high purchase intention. In sum, the shopping mall's target group is mainly shoppers aged $30-40$ years old.

Variable descriptions are shown in Table 1. Sales are calculated by the sum of the consumption by shoppers who enter a store on a day. Considering the store types, we set three dummy variables: Fashion, Catering, and Other. Flow suggests the number of shoppers entering a certain store in a certain period, with Morning representing the sum of shopper flow from the opening time to $11 \mathrm{am}$, Lunch representing the sum of shopper flow from 11 am to $2 \mathrm{pm}$, Afternoon representing the sum of shopper flow from $2 \mathrm{pm}$ to $5 \mathrm{pm}$, Dinner representing the sum of shopper flow from 5 pm until $7 \mathrm{pm}$, and Evening representing the sum of shopper flow from $7 \mathrm{pm}$ to the end of a day. StayTime represents the average length of stay time that shoppers stay in a store after entering the store; Consump is the average consumption of shoppers for a store, and PriceVol is the difference between the average consumption of shoppers in a store and the average consumption of consumers in other stores within the same type.

We use Stata as the statistical software for descriptive statistics, correlational analysis, and regression for spatial econometrics. Table 2 shows the descriptive statistics of the variables. LnSales and lnConsump are the log transformations of the variables Sales and Consump. The shopping mall has a large proportion of fashion stores, followed by catering and other stores. Shopper flow in the afternoon was significantly higher than that in other periods, indicating that shoppers prefer to enter the mall in the afternoon. The average value of stay time is within one minute (48.8653 seconds), suggesting that shoppers are accustomed to walking among different stores. The high standard deviation of PriceVol (S.D. $=1052.002$ ) suggests that the prices of products in different types of stores are highly volatile.

Figure 4 further shows the average and maximum shopper flow in different time intervals. As shown in the figure, the number of consumers reaches the peak during the afternoon period, while the shopping mall is barely crowded during the morning period.

Figure 5 presents the distribution of different types of shops on each floor and shows that fashion shops are mainly concentrated on floors $\mathrm{B} 1$ to $5 \mathrm{~F}$, while catering shops are concentrated on floors $\mathrm{B} 1,6 \mathrm{~F}$ to $9 \mathrm{~F}$.

3.2. Model. Neighboring stores have a certain spatial dependence; thus, this study introduces spatial interaction effects to study the interaction between stores [17]. The basic idea of spatial econometrics is to introduce the interregional relationship into the basic model. The specific method is to set the spatial weight matrix and then introduce the spatial weight matrix into the basic model. According to the different spatial characteristics embodied after the basic model is revised, the spatial measurement model can be divided into two main types: the spatial error model and the spatial autoregressive model. "The first law of geography" points out that stores have geographic dependence and relevance, and spatial measurement models can describe the geographic dependence of stores. 




FIgURE 2: Conceptual framework.

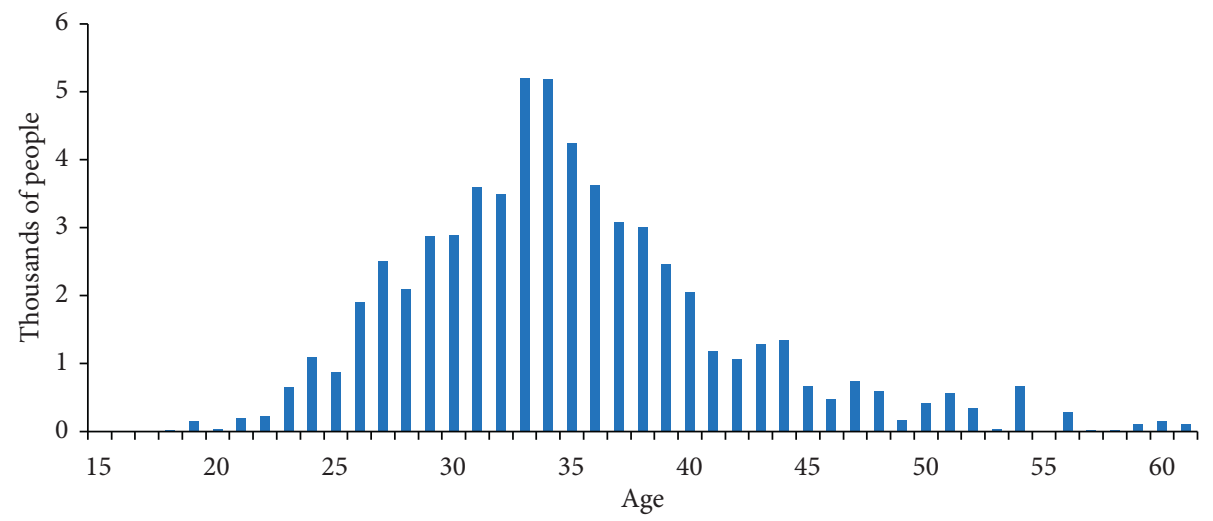

Figure 3: Age distribution of shoppers.

TABLE 1: Variable definitions.

\begin{tabular}{|c|c|c|}
\hline Variable & Description & Calculation \\
\hline Sales & Store sales on one day & The sum of shopper spending for a day. \\
\hline Morning & Morning shopper flow & The sum of shopper flow from opening time to $11 \mathrm{am}$. \\
\hline Lunch & Lunch shopper flow & The sum of shopper flow from 11 am to $2 \mathrm{pm}$. \\
\hline Afternoon & Afternoon shopper flow & The sum of shopper flow from $2 \mathrm{pm}$ to $5 \mathrm{pm}$. \\
\hline Dinner & Dinner shopper flow & The sum of shopper flow from $5 \mathrm{pm}$ to $7 \mathrm{pm}$. \\
\hline Evening & Evening shopper flow & The sum of shopper flow from $7 \mathrm{pm}$ to the end of a day. \\
\hline StayTime & $\begin{array}{l}\text { The average length of shopper } \\
\text { stay time }\end{array}$ & Sum of shopper stay length in a store/the number of shoppers for a store on a day. \\
\hline Consump & The average consumption & er consumption in a store/number of shoppers for a store on a day. \\
\hline PriceVol & The difference in price volatility & $\begin{array}{c}\text { The average consumption of shoppers in a store-the average consumption of shoppers in } \\
\text { other stores within same type. }\end{array}$ \\
\hline
\end{tabular}

This paper studies the influence of the spatial interaction effects of stores on store sales. Spatial lag model (SLM), spatial error model (SEM), and spatial Dubin model (SDM) are employed to calculate the spatial interaction effects of all stores.

Spatial lag model is used in econometric spatial analysis to investigate the effects of a unit sample region on other sample regions within an entire spatial region. Moreover, this model can explore whether there is diffusion of variables across the sample region, also known as spill-over effects [35]. The spatial lags of the explanatory variables allow the research on spatial interactive effect of regional samples, which is the spatial spill-over effect in spatial econometric studies [36]. The expression is shown in

$$
\begin{aligned}
Y & =\rho W Y+\beta X+\varepsilon, \\
\varepsilon & \sim N\left[0, \sigma^{2} I\right] .
\end{aligned}
$$

Because of the spill-over effect of dependent variables, one spatial sample region will pose effects on its nearby sample regions. Thus, the interactive influence between spatial sample regions will appear. This interactive influence 
TABLE 2: Descriptive statistics.

\begin{tabular}{lcccc}
\hline Variable & Mean & S.D. & Minimum & Maximum \\
\hline Sales & 1639.4580 & 5699.0680 & 0 & 252469.2 \\
lnSales & 3.3696 & 3.6484 & 0.0000 & 12.4390 \\
Morning & 1.0909 & 1.1642 & 0 & 4 \\
Lunch & 11.5455 & 9.5049 & 0 & 30 \\
Afternoon & 14.6818 & 13.5965 & 0 & 53 \\
Dinner & 9.3182 & 7.9511 & 0 & 23 \\
Evening & 6.8636 & 5.4131 & 0 & 16 \\
Consump & 334.3968 & 1052.7650 & 0 & 33823 \\
lnConsump & 2.7485 & 2.9748 & 0.0000 & 10.4289 \\
StayTime & 48.8653 & 6.7798 & 36.8226 & 58.7201 \\
PriceVol & -0.0222 & 1052.0020 & -385.4650 & 33478.9400 \\
\hline
\end{tabular}

Note: the average of the PriceVol should be zero theoretically, but the final result varies slightly due to the reserved count bits for numbers after decimal points in the calculation process.

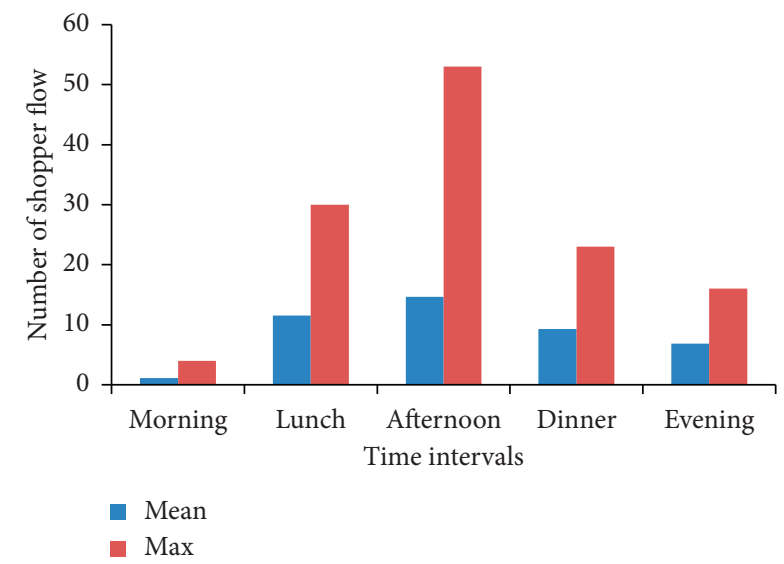

FIgURE 4: Average/maximum shopper flow by time intervals.

can be explored by using spatial effort model through the calculation of spatial dependence in the perturbation term. The spatial error model in equation (2) incorporates the product of residuals and spatial weights in the following equation:

$$
\begin{aligned}
Y & =\beta X+\varepsilon, \\
\varepsilon & =\lambda W+\mu, \\
\mu & \sim N\left[0, \sigma^{2} I\right] .
\end{aligned}
$$

The spatial Durbin model is a fusion of a spatial lag model and a spatial error model. The model includes both dependent variable spatial lag terms and independent variable spatial lag terms. It can alleviate the variable omission issue in the SLM model or SEM model and specify the effect of spatial factors. The expression of spatial Durbin model is shown in

$$
\begin{aligned}
Y & =\rho W Y+\beta X+\gamma W X+\varepsilon, \\
\varepsilon & \sim N\left[0, \sigma^{2} I\right] .
\end{aligned}
$$

In the three equations, $\mathrm{Y}$ is the dependent variable (lnSales) composed of an $(N \times 1)$ vector, and $X$ is an $(\mathrm{NT} \times k)$ matrix. The matrix in this paper is $(737 \times 8)$,

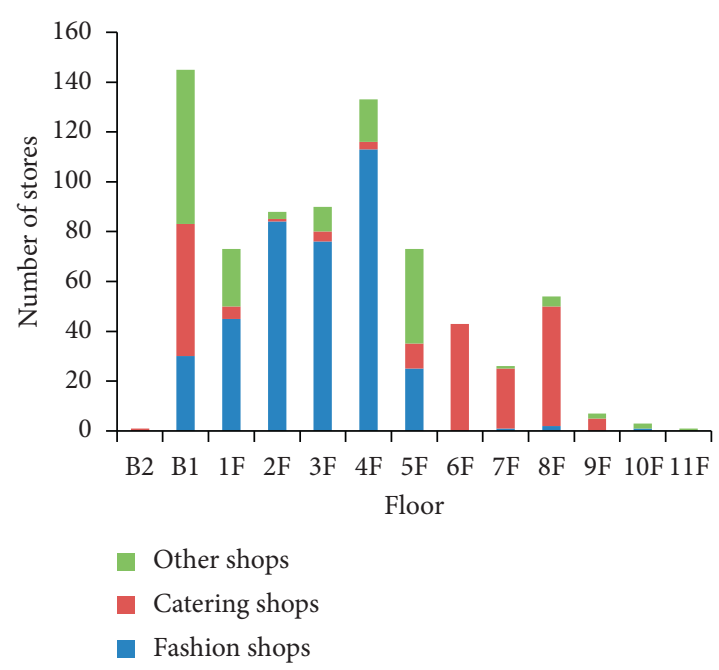

Figure 5: Distribution of different types of stores on each floor.

which represents shopper flow (including the variables Morning, Lunch, Afternoon, Dinner, and Evening) and shopper spending (including variables Consumpt, StayTime, and PriceVol). Additionally, $\lambda$ represents the spatial autocorrelation parameter; $\beta, \rho, \varepsilon$ and I are all $(737 \times 1)$ vectors; and $W$ represents an $(N \times N)$ spatial weight matrix.

Figure 6 shows that if $\gamma=0$, SDM becomes SLM. If $\gamma+\rho \beta=0$, then SDM becomes SLM. SLM describes the interaction of dependent variables between adjacent regions; SEM describes the spatial correlation of error terms; and the dependent variable described by SDM is related to the dependent variable of the local region and the independent variable of the neighboring region. SDM explains more than SLM and SEM in complete sentences.

According to Elhorst and Paul, it is necessary to establish a spatial weight matrix before studying the spatial effect relationship [37]. The spatial weight matrix is based on the geographic distance of the stores in the mall. Since the distance between the stores is fixed, the matrix is symmetric, written as

$$
W=\left[\begin{array}{cccc}
W_{11} & W_{12} & \cdots & W_{1 n} \\
W_{21} & W_{22} & \cdots & W_{2 n} \\
\vdots & \vdots & \vdots & \vdots \\
W_{n 1} & W_{n 2} & \cdots & W_{n n}
\end{array}\right],
$$

and $w_{i j}=w_{j i}, n=737$. We also present the specific matrix in Appendix.

\section{Results}

4.1. Correlation Analysis. Table 3 presents the relationships among variables. Shopper flow in different time periods shows high correlations because shoppers sometimes stay in a shopping mall for a whole day. Shopper consumption is calculated using store sales; thus, there is a high degree of correlation between these two variables. 




FIGURE 6: The relationship between the three spatial measurement models.

TABLE 3: Correlation analysis.

\begin{tabular}{|c|c|c|c|c|c|c|c|c|c|}
\hline & 1 & 2 & 3 & 4 & 5 & 6 & 7 & 8 & 9 \\
\hline 1. $\ln$ Sales & 1 & & & & & & & & \\
\hline 2. Morning & -0.0030 & 1 & & & & & & & \\
\hline 3. Lunch & $-0.1571^{* * *}$ & $0.5542^{* * *}$ & 1 & & & & & & \\
\hline 4. Afternoon & $-0.1795^{* * *}$ & $0.5417^{* * *}$ & $0.830^{* * *}$ & 1 & & & & & \\
\hline 5. Dinner & $-0.1335^{* * *}$ & $0.5714^{* * *}$ & $0.9144^{* * *}$ & $0.7994^{* * *}$ & 1 & & & & \\
\hline 6. Evening & $-0.1199^{* * *}$ & $0.4564^{* * *}$ & $0^{8478^{* * *}}$ & $0.6201^{* * *}$ & $0.8301^{* * *}$ & 1 & & & \\
\hline 7. lnConsump & $0.9730^{* * *}$ & -0.0092 & $-0.1595^{* * *}$ & $-0.1854^{* * *}$ & $-0.1388^{* * *}$ & $-0.1180^{* * *}$ & 1 & & \\
\hline 8. StayTime & $0.2835^{* * *}$ & $-0.0806^{* * *}$ & $-0.2327^{* * *}$ & $-0.2367^{* * *}$ & $-0.1988^{* * *}$ & $-0.4532^{* * *}$ & $0.2538^{* * *}$ & 1 & \\
\hline 9. PriceVol & $0.4371^{* * *}$ & -0.0022 & $-0.0537^{* * *}$ & $-0.0638^{* * *}$ & $-0.0413^{* * *}$ & $-0.0380^{* * *}$ & $0.4980^{* * *}$ & $0.1085^{* * *}$ & 1 \\
\hline
\end{tabular}

Note: Correlation values above 0.8 are denoted in bold. ${ }^{*} p<0.1,{ }^{* *} p<0.05,{ }^{* * *} p<0.01$.

TABLE 4: Fixed-effects model for the full sample.

\begin{tabular}{|c|c|c|c|c|}
\hline & & & & \\
\hline & Main & Wx & SEM & SAC \\
\hline Morning & $\begin{array}{c}0.0953^{* * *} \\
(0.0217)\end{array}$ & $\begin{array}{c}-0.2464^{* * *} \\
(0.0571)\end{array}$ & $\begin{array}{l}0.0122^{* *} \\
(0.0046)\end{array}$ & $\begin{array}{l}-0.0067 \\
(0.0035)\end{array}$ \\
\hline Lunch & $\begin{array}{c}0.0435^{* * *} \\
(0.0070) \\
\end{array}$ & $\begin{array}{c}0.0908^{* * *} \\
(0.0184) \\
\end{array}$ & $\begin{array}{c}-0.0174^{* * *} \\
(0.0015) \\
\end{array}$ & $\begin{array}{c}-0.0107^{* * *} \\
(0.0011)\end{array}$ \\
\hline Afternoon & $\begin{array}{c}0.0025 \\
(0.0031) \\
\end{array}$ & $\begin{array}{c}0.0146 \\
(0.0082) \\
\end{array}$ & $\begin{array}{c}0.0071^{* * *} \\
(0.0007) \\
\end{array}$ & $\begin{array}{c}0.0068^{* * *} \\
(0.0005) \\
\end{array}$ \\
\hline Dinner & $\begin{array}{l}-0.0018 \\
(0.0072)\end{array}$ & $\begin{array}{l}-0.0061 \\
(0.0188) \\
\end{array}$ & $\begin{array}{l}-0.0027 \\
(0.0015) \\
\end{array}$ & $\begin{array}{c}0.0008 \\
(0.0011) \\
\end{array}$ \\
\hline Evening & $\begin{array}{c}0.0650^{* * *} \\
(0.0100)\end{array}$ & $\begin{array}{c}-0.1296^{* * *} \\
(0.0263)\end{array}$ & $\begin{array}{c}0.0296^{* * *} \\
(0.0021) \\
\end{array}$ & $\begin{array}{c}0.0156^{* * *} \\
(0.0017)\end{array}$ \\
\hline InConsump & $\begin{array}{c}1.2008^{* * *} \\
(0.0027) \\
\end{array}$ & $\begin{array}{c}1.5050^{* * *} \\
(0.2152) \\
\end{array}$ & $\begin{array}{c}1.2112^{* * *} \\
(0.0026) \\
\end{array}$ & $\begin{array}{c}1.1981^{* * *} \\
(0.0028) \\
\end{array}$ \\
\hline Staytime & $\begin{array}{c}0.0338^{* * *} \\
(0.0040)\end{array}$ & $\begin{array}{c}-0.0225^{*} \\
(0.0111) \\
\end{array}$ & $\begin{array}{c}0.0288^{* * *} \\
(0.0009) \\
\end{array}$ & $\begin{array}{c}0.0190^{* * *} \\
(0.0088) \\
\end{array}$ \\
\hline PriceVol & $\begin{array}{c}-0.0002^{* * *} \\
(0.0000) \\
\end{array}$ & $\begin{array}{c}0.0052^{* * *} \\
(0.0005) \\
\end{array}$ & $\begin{array}{c}-0.0002^{* * *} \\
(0.0000) \\
\end{array}$ & $\begin{array}{c}-0.0002^{* * *} \\
(0.0000) \\
\end{array}$ \\
\hline$\rho$ & & & & $\begin{array}{c}0.1471^{* * *} \\
(0.0100) \\
\end{array}$ \\
\hline$\lambda$ & & & $\begin{array}{c}-1.0914^{* * *} \\
(0.1439) \\
\end{array}$ & $\begin{array}{c}-2.5184^{* * *} \\
(0.1497) \\
\end{array}$ \\
\hline$\sigma 2 \_\mathrm{e}$ & & & $\begin{array}{c}0.5820^{* * *} \\
(0.0065)\end{array}$ & $\begin{array}{c}0.6034^{* * *} \\
(0.0064)\end{array}$ \\
\hline $\begin{array}{l}R^{2} \\
\text { Log-likelihood }\end{array}$ & & & $\begin{array}{c}0.9495 \\
-18620\end{array}$ & $\begin{array}{c}0.9494 \\
-18550\end{array}$ \\
\hline
\end{tabular}

Note: standard error in brackets and ${ }^{* * *} p<0.01,{ }^{* *} p<0.5$, and $^{*} p<0.1$. 
TABLE 5: SDM of fashion/catering/other stores.

\begin{tabular}{|c|c|c|c|c|c|c|c|c|}
\hline & \multicolumn{2}{|c|}{ SDM } & \multicolumn{2}{|c|}{ SDM_fashion } & \multicolumn{2}{|c|}{ SDM_catering } & \multicolumn{2}{|c|}{ SDM_other } \\
\hline & Main & WX & Main & WX & Main & WX & Main & WX \\
\hline Morning & $\begin{array}{c}0.0953^{* * *} \\
(0.0217)\end{array}$ & $\begin{array}{c}-0.2464^{* * *} \\
(0.0571)\end{array}$ & $\begin{array}{l}0.0625^{*} \\
(0.0243)\end{array}$ & $\begin{array}{c}-0.6555^{* *} \\
(0.2130)\end{array}$ & $\begin{array}{l}-0.0653 \\
(0.0539)\end{array}$ & $\begin{array}{c}0.4981 \\
(0.4289)\end{array}$ & $\begin{array}{c}0.0302 \\
(0.0405)\end{array}$ & $\begin{array}{l}-0.3580 \\
(0.4777)\end{array}$ \\
\hline Lunch & $\begin{array}{c}-0.0435^{* * *} \\
(0.0070)\end{array}$ & $\begin{array}{c}0.0908^{* * *} \\
(0.0184) \\
\end{array}$ & $\begin{array}{c}-0.0546^{* * *} \\
(0.0078)\end{array}$ & $\begin{array}{c}0.2867^{* * *} \\
(0.0695) \\
\end{array}$ & $\begin{array}{l}-0.0217 \\
(0.0173)\end{array}$ & $\begin{array}{c}0.1393 \\
(0.1390) \\
\end{array}$ & $\begin{array}{c}-0.0248 \\
(0.0130) \\
\end{array}$ & $\begin{array}{c}0.1603 \\
(0.1543) \\
\end{array}$ \\
\hline Afternoon & $\begin{array}{c}0.0025 \\
(0.0031) \\
\end{array}$ & $\begin{array}{c}0.0146 \\
(0.0082) \\
\end{array}$ & $\begin{array}{c}0.0156^{* * *} \\
(0.0035) \\
\end{array}$ & $\begin{array}{l}-0.0386 \\
(0.0311) \\
\end{array}$ & $\begin{array}{c}0.0689^{* * *} \\
(0.0079)\end{array}$ & $\begin{array}{c}-0.5046^{* * *} \\
(0.0643) \\
\end{array}$ & $\begin{array}{c}0.0035 \\
(0.0058)\end{array}$ & $\begin{array}{c}0.0101 \\
(0.0686)\end{array}$ \\
\hline Dinner & $\begin{array}{l}-0.0018 \\
(0.0072)\end{array}$ & $\begin{array}{l}-0.0061 \\
(0.0188)\end{array}$ & $\begin{array}{l}-0.0034 \\
(0.0080)\end{array}$ & $\begin{array}{c}0.0890 \\
(0.0697)\end{array}$ & $\begin{array}{c}-0.0370^{*} \\
(0.0179)\end{array}$ & $\begin{array}{c}0.2383 \\
(0.1444)\end{array}$ & $\begin{array}{l}-0.0031 \\
(0.0133)\end{array}$ & $\begin{array}{c}0.0405 \\
(0.1569)\end{array}$ \\
\hline Evening & $\begin{array}{c}0.0650^{* * *} \\
(0.0100)\end{array}$ & $\begin{array}{c}-0.1296^{* * *} \\
(0.0263)\end{array}$ & $\begin{array}{c}0.0717^{* * *} \\
(0.0109)\end{array}$ & $\begin{array}{c}-0.3514^{* * *} \\
(0.0979)\end{array}$ & $\begin{array}{c}-0.0715^{* *} \\
(0.0247)\end{array}$ & $\begin{array}{c}0.6355^{* *} \\
(0.1977)\end{array}$ & $\begin{array}{l}0.0397^{*} \\
(0.0182)\end{array}$ & $\begin{array}{l}-0.1893 \\
(0.2203)\end{array}$ \\
\hline $\operatorname{lnConsump}$ & $\begin{array}{c}1.2008^{* * *} \\
(0.0027)\end{array}$ & $\begin{array}{c}1.5050^{* * *} \\
(0.2152) \\
\end{array}$ & $\begin{array}{c}1.1855^{* * *} \\
(0.0036)\end{array}$ & $\begin{array}{c}5.3953^{* * *} \\
(0.8557) \\
\end{array}$ & $\begin{array}{c}1.2280^{* * *} \\
(0.0056) \\
\end{array}$ & $\begin{array}{c}-5.7051^{* * *} \\
(0.6341) \\
\end{array}$ & $\begin{array}{c}1.1954^{* * *} \\
(0.0056) \\
\end{array}$ & $\begin{array}{c}1.0236 \\
(1.4177) \\
\end{array}$ \\
\hline Staytime & $\begin{array}{c}0.0338^{* * *} \\
(0.0040) \\
\end{array}$ & $\begin{array}{c}-0.0225^{*} \\
(0.0111) \\
\end{array}$ & $\begin{array}{c}0.0412^{* * *} \\
(0.0044)\end{array}$ & $\begin{array}{c}0.1215^{* *} \\
(0.0420) \\
\end{array}$ & $\begin{array}{c}0.0167 \\
(0.0097) \\
\end{array}$ & $\begin{array}{l}-0.0021 \\
(0.0802) \\
\end{array}$ & $\begin{array}{c}0.0274^{* * *} \\
(0.0074)\end{array}$ & $\begin{array}{l}-0.1048 \\
(0.0933) \\
\end{array}$ \\
\hline PriceVol & $\begin{array}{c}-0.0002^{* * *} \\
(0.0000)\end{array}$ & $\begin{array}{c}0.0052^{* * *} \\
(0.0005)\end{array}$ & $\begin{array}{c}-0.0002^{* * *} \\
(0.0000)\end{array}$ & $\begin{array}{c}-0.0051^{* * *} \\
(0.0011)\end{array}$ & $\begin{array}{c}-0.0002^{* * *} \\
(0.0000)\end{array}$ & $\begin{array}{c}0.0027^{*} \\
(0.0012)\end{array}$ & $\begin{array}{c}-0.0002^{* * *} \\
(0.0000)\end{array}$ & $\begin{array}{c}-0.0050^{* * *} \\
(0.0014)\end{array}$ \\
\hline$\rho$ & \multicolumn{2}{|c|}{$\begin{array}{c}-1.6453^{* * *} \\
(0.1596)\end{array}$} & \multicolumn{2}{|c|}{$\begin{array}{c}-2.8208^{* * *} \\
(0.6164)\end{array}$} & \multicolumn{2}{|c|}{$\begin{array}{c}4.0075^{* * *} \\
(0.4367)\end{array}$} & \multicolumn{2}{|c|}{$\begin{array}{c}0.1753 \\
(1.0903) \\
\end{array}$} \\
\hline$\sigma 2 \_\mathrm{e}$ & \multicolumn{2}{|c|}{$\begin{array}{c}0.5714^{* * *} \\
(0.0063)\end{array}$} & \multicolumn{2}{|c|}{$\begin{array}{c}0.5410^{* * *} \\
(0.0084)\end{array}$} & \multicolumn{2}{|c|}{$\begin{array}{c}0.6038^{* * *} \\
(0.0130)\end{array}$} & \multicolumn{2}{|c|}{$\begin{array}{c}0.5619^{* * *} \\
(0.0133)\end{array}$} \\
\hline $\begin{array}{l}R 2 \\
\text { Log-likelihood }\end{array}$ & \multicolumn{2}{|c|}{$\begin{array}{c}0.9502 \\
-18470\end{array}$} & \multicolumn{2}{|c|}{0.9554} & \multicolumn{2}{|c|}{0.9377} & \multicolumn{2}{|c|}{0.9537} \\
\hline
\end{tabular}

Note: standard error in brackets, and ${ }^{* * *} p<0.01,{ }^{* *} p<0.5$, and ${ }^{*} p<0.1$.

4.2. Hypothesis Testing. A Hausman test was first performed to determine the specific form of the model. The result rejects the nonsystematic null hypothesis of the difference in regression coefficients between fixed-effects and randomeffects models, making fixed-effect spatial Dubin model the appropriate method in this study.

Table 4 shows the full sample's regression results containing data for all types of stores. The $\rho$ of the SDM model in Table 4 is significantly negative, indicating that the sales of a store have spatial interaction effects and inhibitory effects on the surrounding stores. That is, when InSales of surrounding stores increases by $1 \%$, InSales of a brand store will decrease by $1.6453 \%$. The coefficient of StayTime is significant and positive, suggesting that a longer length of time that a shopper stays in a store can increase store sales. Thus, H1 and $\mathrm{H} 2$ are supported.

The number of shoppers entering a store in the morning and evening (shopper flow in the morning and evening) will effectively increase the store's sales; in contrast, the number of shoppers entering a store at lunch (shopper flow in the lunch) will reduce the sales of the store, while the number of shoppers entering the store during the afternoon and dinner has no significant impact on sales. The possible reasons are as follows. (1) Based on the results of the descriptive analysis, the highest number of shoppers entering a store at lunch is almost twice that entering a store in the morning and evening ( $\max$ $($ Lunch $)=30, \max ($ Morning, Evening $)=16)$. This overcrowded environment at lunch may inhibit shoppers' desire regarding purchase decisions. (2) Besides catering stores, other types of stores tend to appeal fewer shoppers to buy goods at lunch. Thus, H3 is supported.

We then separate full sample into three subsamples according to the type of stores and conduct similar regression with Table 4 . The results are shown in Table 5.

Fashion and catering have spatial interaction effects. For fashion stores, as the sales in the surrounding stores increase by $1 \%$, the sales of a brand store will decrease by $2.8208 \%$; for catering stores, as the sales of the surrounding stores increase by $1 \%$, the sales of a brand store will increase by $4.0075 \%$. Thus, $\mathrm{H} 4$ is supported. The reason may due to the concentration of catering shops on $6 \mathrm{~F}, 8 \mathrm{~F}$, and $\mathrm{B} 1$ (74.6\% of the total), which may trigger the herding influence and then increase the sales of similar stores in the same region. The results also indicate that the influence of shopper stay time on sales of a brand store is higher for fashion stores than for catering stores $(4.12 \%$ $>1.67 \%$ ). The possible reason is that the stay time of shoppers for catering stores is excessively long and reaches the carrying limit of a shopping mall or a store, thus restricting the effect of shopper stay time on sales for a brand store.

\section{Conclusion}

This study investigates the influencing factors of store sales in a large shopping mall from the perspective of spatial measurement. By collecting shopper consumption information, shopper movement data, and store location data from September 23, 2016, to October 9, 2016, this study 
established a spatial measurement regression equation and obtained the following findings.

First, there is a significant sales association between stores in a shopping mall. As sales of surrounding stores increase, sales of a brand store decrease. After a shopper purchases a certain product, the satisfaction of shopping will temporarily reduce the desire to obtain the next product. The attention and budget of the shopper may also be used up for the product, leaving less for other products in surrounding stores. The impact is particularly noticeable for fashion stores, as shoppers may only intend to buy one or two products in such stores. The situation is quite different for catering stores with a concentrated distribution, as such stores are more likely to gather shoppers with long-time stays in a short time. For a limited space within an area, large number of shoppers will spill to other stores within this area. Therefore, the spatial interaction effect of catering stores can reduce the negative influence of sales of surrounding stores on sales of a brand store.

Second, the sales of a brand store are significantly affected by shopper stay time and shopper flow of surrounding stores. The increase in shopper flow or stay time in surrounding stores reduces the sales of a brand store. Previous studies have found that longer stay times in stores can effectively increase shopper spending [26]. Similar to, but going beyond, previous studies, this study found that longer stay times in the surrounding stores can increase the sales of the surrounding stores but reduce the sales of a brand store. Shopper flow and stay time are fixed within a certain range. When shoppers visit and stay more in surrounding stores, they will inevitably reduce the visit and stay in a brand store. For fashion stores, shopper flow of the surrounding stores negatively affects sales of a brand store in the morning and evening; for catering stores, the phenomenon is similar in the afternoon, while for fashion stores, shopper flow of the surrounding stores could bring positive impacts to the sales of a brand store during lunch time. The situation is similar for catering stores in dinner and evening periods.

5.1. Theoretical Implications. This study makes several theoretical contributions. First, this study extends limited attention to the context of LBSs. Prior studies have already recognized the importance of limited attention and investigated it in several areas, especially in financial markets [38]. For example, investors pay less attention to firm news on Fridays, because they are distracted by other activities [39]. Although marketing scholars have begun to explore the limited attention of shoppers [40], it is still unclear how shoppers' limited attention influences sales associations between brand stores and the surrounding stores. This study employs limited attention to explain the sales of surrounding stores regarding brand stores and contributes to the limited attention literature by introducing a new context for it.

Second, this study complements the literature on herding influences concerning LBSs. Existing studies about herding influence have already identified its influence in several contexts, such as crowdfunding platforms and technology adoption websites $[41,42]$. However, how different types of stores induce different herding influences and break traditional sales associations is still unknown. Compared to fashion stores and other stores, catering stores are more agminated and likely to be patronized by consumers due to herding influence, which can alleviate the negative influence of sales of surrounding stores on a brand store. These findings shed light on more application areas regarding herding influence.

Last, this study extends consumer behavior literature, especially those in time-space relationships based on LBS applications. The limitation of technology makes it difficult to obtain shopper data in space and time. The application of LBS can help us track the movement trajectory and action status of shoppers in offline brand stores and obtain firsthand data for further analysis. This study identifies several positioning factors for a brand store in an offline shopping mall through long-term data collection on shopper movement and purchase decisions, thus extending existing consumer behavior studies.

5.2. Practical Implications. This study also has several practical implications. First, this study highlights the importance of an existing marketing tool-LBSs. LBSs based on spatial interaction effects have been widely used in online applications, while the applications in offline contexts are still rare. By identifying the value of LBSs within a large shopping mall in China, this study suggests that the adoption of LBSs can help shopping malls understand shopper behavior and make better strategies. Thus, we encourage shopping malls to actively deal with LBSs. Second, this study finds that, for catering stores, sales associations based on locations are quite different compared to those for other types of stores. Thus, this study suggests specific location arrangements for stores with different features. For example, shopping mall operators can create a centralized catering area and design an effective layout for fashion stores. In this way, shopping malls can maximize the promotional effects between stores and reduce the competitive relationship among surrounding stores.

5.3. Limitations. This study has several limitations. First, store and shopper characteristics are not included in the data, restricting the understanding of the relationship or mutual influence between stores and shoppers. Second, this research only categorizes stores in fashion and catering categories according to general attributes. A more detailed classification of stores based on shopper groups or other detailed indicators may help us obtain a more integrated result. Third, this study only collected data from stores within one shopping mall. Although data in one shopping mall are commonly used in marketing articles, we intend to cooperate with more shopping malls. In this way, we can obtain a more robust result and consider the effect of broader geographic features on store competition relationships. 


\section{Data Availability}

Data are available upon request to the corresponding author.

\section{Conflicts of Interest}

The authors declare no conflicts of interest.

\section{References}

[1] S. Barnes, "Location-based services: the state of the art," $E$ Service Journal, vol. 2, no. 3, pp. 59-70, 2003.

[2] X. Heng and S. Gupta, "The effects of privacy concerns and personal innovativeness on potential and experienced customers' adoption of location-based services," Electronic Markets, vol. 19, no. 2-3, pp. 137-149, 2009.

[3] X. Heng, H. H. Teo, B. C. Tan, and R. Agarwal, "The role of push-pull technology in privacy calculus: the case of locationbased services," Journal of Management Information Systems, vol. 26, no. 3, pp. 135-174, 2009.

[4] S. Dhar and U. Varshney, "Challenges and business models for mobile location-based services and advertising," Communications of the ACM, vol. 54, no. 5, pp. 121-128, 2011.

[5] Z. Farid, R. Nordin, and M. Ismail, "Recent advances in wireless indoor localization techniques and system," Journal of Computer Networks and Communications, vol. 2013, Article ID 185138, 12 pages, 2013.

[6] H. Yun, D. Han, and C. C. Lee, "Understanding the use of location-based service applications: do privacy concerns matter?" Journal of Electronic Commerce Research, vol. 14, no. 3, p. 215, 2013.

[7] I. D. Constantiou, C. Lehrer, and T. Hess, "Changing information retrieval behaviours: an empirical investigation of users' cognitive processes in the choice of location-based services," European Journal of Information Systems, vol. 23, no. 5, pp. 513-528, 2014.

[8] P. Reichhart, "Identifying factors influencing the customers purchase behaviour due to location-based promotions," International Journal of Mobile Communications, vol. 12, no. 6 , pp. 642-660, 2014.

[9] S. A. Basheir and A. Z. Karrar, "The impact of service quality on customer satisfaction in location based service:(mishwar and tirhal as case studies)," in Proceedings of the 2019 International Conference on Computer, Control, Electrical, and Electronics Engineering (ICCCEEE), pp. 1-6, Khartoum, Sudan, September 2019.

[10] K. L. Hsiao, "What drives continuance intention to share location-based information?" International Journal of Mobile Communications, vol. 15, no. 2, pp. 210-233, 2017.

[11] C. Lehrer, I. Constantiou, and T. Hess, "Exploring use patterns and perceived value of location-based services," in Proceedings of the 2010 Ninth International Conference on Mobile Business and 2010 Ninth Global Mobility Roundtable (ICMB-GMR), pp. 107-115, Athens, Greece, June 2010.

[12] A. G. Powell, "The shopping mall high school. Winners and losers in the educational marketplace," NASSP Bulletin, vol. 69, no. 483, pp. 40-51, 1985.

[13] E. C. Hirschman, "Intratype competition among department stores," Journal of Retailing, vol. 55, no. 4, pp. 20-34, 1979.

[14] P. J. Kaufmann, N. Donthu, and C. M. Brooks, "Multi-unit retail site selection processes: incorporating opening delays and unidentified competition," Journal of Retailing, vol. 76, no. 1, pp. 113-127, 2000.
[15] V. Aguirregabiria and G. Vicentini, "Dynamic spatial competition between multi-store retailers," The Journal of Industrial Economics, vol. 64, no. 4, pp. 710-754, 2016.

[16] P. Davis, "Spatial competition in retail markets: movie theaters," The RAND Journal of Economics, vol. 37, no. 4, pp. 964-982, 2006.

[17] B. J. Bronnenberg and V. Mahajan, "Unobserved retailer behavior in multimarket data: joint spatial dependence in market shares and promotion variables," Marketing Science, vol. 20, no. 3, pp. 284-299, 2001.

[18] M. Luca and G. Zervas, "Fake it till you make it: reputation, competition, and yelp review fraud," Management Science, vol. 62 , no. 12 , pp. 3412-3427, 2016.

[19] D. Mayzlin, Y. Dover, and J. Chevalier, "Promotional reviews: an empirical investigation of online review manipulation," American Economic Review, vol. 104, no. 8, pp. 2421-2455, 2014.

[20] D. Kahneman, Attention and Effort, Prentice-Hall, Englewood Cliffs, NJ, USA, 1973.

[21] B. Rattray, C. Argus, K. Martin, J. Northey, and M. Driller, "Is it time to turn our attention toward central mechanisms for post-exertional recovery strategies and performance?" Frontiers in Physiology, vol. 6, no. 79, 2015.

[22] A. V. Banerjee, "A simple model of herd behavior," The Quarterly Journal of Economics, vol. 107, no. 3, pp. 797-817, 1992.

[23] A. Ghosh and S. L. MacLafferty, Location Strategies for Retail and Service Firms, Lexington Books, Washington, DC, USA, 1987.

[24] J. Hornik, "Subjective vs. objective time measures: a note on the perception of time in consumer behavior," Journal of Consumer Research, vol. 11, no. 1, pp. 615-618, 1984.

[25] T. Nakahara and K. Yada, "Analyzing consumers' shopping behavior using RFID data and pattern mining," Advances in Data Analysis and Classification, vol. 6, no. 4, pp. 355-365, 2012.

[26] K. Takai and K. Yada, "A framework for analysis of the effect of time on shopping behavior," Journal of Intelligent Information Systems, vol. 41, no. 1, pp. 91-107, 2013.

[27] S. K. Hui, E. T. Bradlow, and P. S. Fader, "Testing behavioral hypotheses using an integrated model of grocery store shopping path and purchase behavior," Journal of Consumer Research, vol. 36, no. 3, pp. 478-493, 2009.

[28] Y. Cai and R. Shannon, "Personal values and mall shopping behavior: the mediating role of attitude and intention among Chinese and Thai consumers," Australasian Marketing Journal, vol. 20, no. 1, pp. 37-47, 2012.

[29] S. Datla, P. Sahu, H.-J. Roh, and S. Sharma, "A comprehensive analysis of the association of highway traffic with winter weather conditions," Procedia - Social and Behavioral Sciences, vol. 104, pp. 497-506, 2013.

[30] T. Ishikura, "A practical modeling of international air passenger flow in the east asia," Infrastructure Planning Review, vol. 23, pp. 479-488, 2006.

[31] D. Soper, C. Baker, and M. Sterling, "Experimental investigation of the slipstream development around a container freight train using a moving model facility," Journal of Wind Engineering and Industrial Aerodynamics, vol. 135, pp. 105117, 2014

[32] R. J. Graham, "The role of perception of time in consumer research," Journal of Consumer Research, vol. 7, no. 4, pp. 335-342, 1981. 
[33] M. M. Bergadaa, "The role of time in the action of the consumer," Journal of Consumer Research, vol. 17, no. 3, pp. 89-302, 1990.

[34] Y.-C. Chiou and C.-H. Liu, "Advance purchase behaviors of air passengers: a continuous logit model," Transportation Research Part E: Logistics and Transportation Review, vol. 93, pp. 474-484, 2016.

[35] M. Li and L. L. Bao, "Analysis of changes in the impact of public infrastructure investment on the regional economy during the transition period," Statistics \& Decision, vol. 3, pp. 150-154, 2017.

[36] Y. P. Fang, M. Xie, and Z. P. Lin, "A spatial econometric analysis of impact of ICT on service innovation: based on analysis of 21 cities in Guangdong Province," Acta Geographica Sinica, vol. 68, no. 8, pp. 1119-1130, 2013.

[37] E. J. Paul, "Applied spatial econometrics: raising the bar," Spatial Economic Analysis, vol. 5, no. 1, pp. 9-28, 2010.

[38] D. Hirshleifer and S. H. Teoh, "Limited attention, information disclosure, and financial reporting," Journal of Accounting and Economics, vol. 36, no. 1-3, pp. 337-386, 2003.

[39] H. Louis and A. Sun, "Investor inatftention and the market reaction to merger announcements," Management Science, vol. 56, no. 10, pp. 1781-1793, 2010.

[40] E. Jaakkola, A. Helkkula, L. Aarikka-Stenroos, and A. Dube, "Service experiences beyond the direct use: indirect customer use experiences of smartphone apps," Journal of Service Management, vol. 26, no. 2, pp. 224-248, 2015.

[41] Y. Jiang, Y.-C. Ho, X. Yan, and Y. Tan, "Investor platform choice: herding, platform attributes, and regulations," Journal of Management Information Systems, vol. 35, no. 1, pp. 86116, 2018.

[42] H. Sun, "A longitudinal study of herd behavior in the adoption and continued use of technology," MIS Quarterly, vol. 37, no. 4, pp. 1013-1041, 2013. 